\title{
A lírica e a sociedade na produção literária de Manoel de Barros
}

Bianca Albuquerque da Costa ${ }^{1}$

RESUMO: O presente artigo pretende debater de que forma a escrita de Manoel de Barros, que se mostra como uma escrita aparentemente despropositada, carregada de ilogismos, que trabalha com as coisas mais corriqueiras e ligadas à natureza, apresenta ao leitor o social, como a lírica e a sociedade se relacionam dentro da obra poética de Manoel de Barros.

ABSTRACT: This article aims to debate how the allegedly purposeless Manoel de Barros' writings, while being charged with senselessness, work with the most trivial and natural things, as to present the social to the reader, and to show how lyricism and society interact in his poetry.

PALAVRAS-ChAVE: Poesia; Sociedade; Utilidade KEYWORDS: Poetry; Society; Usefulness

Theodor W. Adorno, em sua "Palestra sobre lírica e sociedade", afirma que "o eu que ganha voz na lírica é um eu que se determina e exprime como oposto ao coletivo, à objetividade". (2003, p. 70) Na poesia de Manoel de Barros, essa oposição ao domínio do pensamento comum pode ser observada no desprezo por aquilo que a sociedade julga ser útil e, consequentemente, por seu gosto por tudo o que ela,

1 Mestre pela Universidade Federal do Ceará. Título da pesquisa: Manoel de Barros: peraltices e traquinagens com a palavra poética. 
de modo geral, rejeita, ignora ou mesmo considera como lixo. O traste, na obra de Barros, possui importância, é matéria de poesia e chega a merecer uma "teologia", a "Teologia do traste":

As coisas jogadas fora por motivo de traste são alvo da minha estima.

Prediletamente latas.

Latas são pessoas léxicas pobres porém concretas.

Se você jogar na terra uma lata por motivo de traste: mendigos, cozinheiras ou poetas podem pegar.

Por isso eu acho as latas mais suficientes, por exemplo, do que as ideias.

Porque as ideias, sendo objetos concebidos pelo espírito, elas são abstratas.

E, se você jogar um objeto abstrato na terra por motivo de traste, ninguém quer pegar.

Por isso eu acho as latas mais suficientes.

A gente pega uma lata, enche de areia e sai puxando pelas ruas moda um caminhão de areia. $(\ldots)$

(BARROS, 2007b, p.47)

Nesse poema, percebe-se claramente a inversão dos valores comuns feita por Manoel de Barros. Para o poeta, a ideia, tão difundida pela sociedade como fonte do saber, principio de tudo e base importante para o conhecimento, é objeto de desprezo. Ao contrário, a lata adquire status de coisa principal, não qualquer lata, mas aquela que foi jogada fora, que estava em ponto de traste. O contraponto estabelecido entre a qualidade abstrata da ideia e a concretude da lata poderia sugerir uma sobreposição do que é material ao que não possui existência concreta como forma de exaltação do materialismo ou mesmo do consumismo, tão arraigado em nossa sociedade. Mas, ao fazer referência e exaltar o lixo, o que é rejeitado, o autor foge do senso comum e se opõe à ideia coletiva de 
que o lixo deve ser descartado e as ideias, sublimadas. Pode-se afirmar que, no texto, a lata não é o objeto em si, mas representa a palavra, o substantivo concreto que constrói o poema, que não se esvai ou se esconde como as ideias, mas que se mostra, permanece e difunde-se entre os leitores. Observa-se, dessa forma, outro ponto importante na escrita de Manoel de Barros, a questão do que pode ser matéria de poesia. E, nesse aspecto, nota-se um rompimento quase que total com os conceitos coletivos. Manoel de Barros afasta-se de todos os padrões, traz o inusitado para sua escrita e, com isso, provoca, a todos nós, leitores, acostumados com o que o senso comum estabelece como elementos poéticos e, assim, vemos nossa lógica desafiada, nossas bases estremecidas. Essa característica pode ser melhor observada em "Matéria de poesia":

Todas as coisas cujos valores podem ser

disputados no cuspe da distância

servem para poesia

(...)

As coisas que não levam a nada

têm grande importância

Cada coisa ordinária é um elemento de estima

(...)

Tudo aquilo que a nossa

civilização rejeita, pisa e mija em cima, serve para poesia

(...)

O que é bom para o lixo é bom para a poesia

(...)

As coisas jogadas fora

têm grande importância

- como um homem jogado fora

(...)

As coisas sem importância são bens da poesia (...)

(BARROS, 2001, p.11-15) 
Aqui, também pode ser constatada uma oposição à objetividade e à coletividade, pois o poeta foge dos chamados grandes temas da poesia e, com isso, traz para seu universo lírico palavras simples, ou corriqueiras, que nomeiam coisas consideradas, de um modo geral, como de menor importância, sem valor, sem préstimo para a sociedade ou mesmo para a poesia. Esses elementos são resgatados por ele e transformam-se em verdadeiras preciosidades da linguagem, pois se poetizam e ganham ar de novidade dentro da obra. O lixo, as latas, o cuspe, as lagartixas e, até mesmo, um "chevrolé gosmento" (BARROS, p. 11) encontram espaço na arte poética de Barros, que consegue, assim, fugir ao senso comum do que é considerado matéria de poesia.

Essa oposição ao coletivo não é uma negação da natureza social da lírica; antes, é a consolidação de sua presença. Da mesma forma, Adorno (p. 68-69) vai afirmar que a busca pela palavra virginal, tão inerente à expressão lírica, também é uma exigência social, pois nasce do protesto do indivíduo que vive uma situação opressiva e hostil. E a configuração lírica responde a essa situação resistindo inflexivelmente, criando suas próprias leis para buscar sua liberdade criativa.

Manoel de Barros busca incansável essa palavra em estado virginal como se pode observar em "Retrato quase apagado em que se pode perfeitamente ver nada":

Nas Metamorfoses, em duzentas e quarenta fábulas, Ovídio mostra seres humanos transformados em pedras, vegetais, bichos, coisas.

Um novo estágio seria que os entes já transformados falassem um dialeto coisal, larval, pedral etc. Nasceria uma linguagem madruguenta, adâmica, edênica, inaugural -

Que os poetas aprenderiam - desde que voltassem às [crianças que foram 
Às rãs que foram

Às pedras que foram.

(BARROS, 1998, p.64)

O poeta pretende alcançar o estado mais primitivo das palavras, numa tentativa de resgatar algo de anterior ao próprio conceito, e isso se torna possivel por meio do contato com o que há de mais rústico, como as pedras, larvas e rãs. Ele quer alcançar uma linguagem "adâmica", "edênica”, não no sentido bíblico, nem, ao menos, através de um olhar religioso que pretende a reconstrução do paraíso; o que ele deseja é um retorno ao que é originário, à linguagem fundadora advinda dos primórdios do mundo. E o retorno a essa linguagem não conceitual, a essa linguagem de fonte, se torna possivel, dentro do devaneio, a partir do momento em que também o homem, o poeta, resgata suas origens, os estados animal, vegetal e mineral inerentes a ele. Essa busca constante pela palavra inaugural, por aquilo que Barros afirma ser o "criançamento das palavras" (BARROS, 2006, p. 47), não é apenas um movimento subjetivo, mas uma resposta a toda opressão e rotulação do mundo, e pensamento, contemporâneo. O poeta foge do que é costumeiro e tenta alcançar um estado primitivo das palavras e, desse modo, consegue burlar o imediatismo, a leitura facilitada, a banalização e a massificação da cultura tão presentes nos dias atuais. Assim, "quanto mais essa situação pesa sobre ela (a lírica), mais inflexivelmente a configuração resiste, não se curvando a nada de heterônomo e constituindo-se inteiramente segundo suas próprias leis.” (ADORNO, p. 69)

Há, então, uma objetividade presente na lírica, que é, também, fruto de sua própria subjetividade, mas isso somente se torna possivel se a motivação social não for o objetivo primeiro, isto é, se ela acontecer "por sobre a cabeça do autor". (ADORNO, p. 74) Essa relação entre a subjetividade e a objetividade dentro da lírica só é possivel por meio da linguagem. A linguagem é, em si mesma, algo 
duplo, pois é o meio de expressão da subjetividade do autor e, ao mesmo tempo, não deixa de ser "o meio dos conceitos" (ADORNO, p. 74) que sempre estabelece uma ligação com a sociedade e o universal. Adorno afirma que as composições líricas mais relevantes são justamente "aquelas nas quais o sujeito, sem qualquer resíduo de mera matéria, soa na linguagem, até que a própria linguagem ganha voz" (p. 74). E essa propriedade da linguagem que ganha vida e voz dentro da poesia é uma característica marcante das obras de Manoel de Barros. É uma preocupação do próprio autor a busca pela palavra, pela máxima expressão nos poemas e ele chega a afirmar:

É a palavra que me vai desvelando. Eu fico só a veire. De repente estou mais perto de mim que esta cadeira em que me sento. A palavra me leva para as paixões e os hospitais. Me deforma e me refaz. A vida da gente se torna o texto. (Está cheirando a Heidegger.) Verifico no meio de tudo que ela, a palavra, é mais erótica do que eu.(...)

A palavra me vai revelando. Um dia me mostra conspícuo. No outro dia venéreo. (BARROS, apud BARBOSA, 2003, p. 124)

A declaração de Barros parece coadunar-se com as palavras de Adorno, pois o poeta afirma que, ao se entregar às palavras, à linguagem, acontece uma aproximação ao seu próprio eu. A rendição às palavras revela, então, o próprio sujeito e ocorre uma simbiose entre a linguagem e esse sujeito que passa a se reconhecer na escrita e vê sua vida se tornar um texto. A escrita que aflora e parece ter uma existência independente do autor, já que ele mesmo afirma que permanece somente a "veire", acaba por revelá-lo, por mostrar seu lado mais intimo e subjetivo, pois o "deforma", o "refaz", o modifica através de suas construções a partir do momento em que o poeta se esquece e se entrega a ela. E esse momento de sujeição, em que o 
autor se esquece na linguagem, não é um momento de violência, ou mesmo aniquilamento do sujeito, justamente porque esse mesmo sujeito acaba por se revelar na linguagem, pois

O instante de autoesquecimento, no qual o sujeito submerge na linguagem, não consiste no sacrificio do sujeito ao Ser. Não é um instante de violência contra o sujeito, mas um instante de reconciliação: a linguagem fala por si mesma apenas quando deixa falar como algo alheio e se torna a própria voz do sujeito. Onde o eu se esquece na linguagem, ali ele está inteiramente presente; (...) (ADORNO, p. 75)

A linguagem revela, então, o subjetivo e, ao mesmo tempo, o social, traçando uma mediação entre eles no que há de mais intrínseco (ADORNO, p. 74), pois ela nasce da expressão de um sujeito, mas, por mais que esse sujeito busque um rompimento com a tradição ou com o olhar comum, sua linguagem estará sempre ligada ao que há de social e universal, porque essa é sua natureza.

Assim, a lírica mostra com mais propriedade seu lado social justamente no momento em que se afasta daquilo que a sociedade pretende ver e quando o sujeito consegue alcançar uma harmonia com a linguagem, deixando-a em liberdade para trilhar os caminhos que ela desejar (ADORNO, p. 74). E é dessa maneira que conseguimos perceber o social na lírica de Manoel de Barros. Através de sua produção poética aparentemente sem propósito, Barros se entrega à linguagem, ao trabalho com as palavras, deixando-as livres para escolher seu caminho, mas, ao mesmo tempo refletindo-se nelas, desse modo, acaba por imprimir sua subjetividade e, paradoxalmente, trazer uma universalidade a suas obras. Dois poemas serão utilizados para exemplificar a presença do social na escrita de Manoel de Barros por meio de uma análise mais detalhada, visto que os anteriormente mostrados foram observados apenas superficialmente. Pode-se destacar, desde já, que o teor social não está explícito, mas se encontra subentendido na estrutura de ambos os textos, pois como 
afirma Adorno "uma corrente subterrânea coletiva é o fundamento de toda lírica individual" (p. 77).

O primeiro texto selecionado se chama "No Sítio":

A gente morava no Sítio, duas léguas da Capital. Na estrada de terra que passava no Sítio só tinha três vacas, três cabras vadias, um bandarra velho e a égua Floripa.

Meu avô queria passear na Capital.

Mandou encilhar Floripa. E saiu.

No meio da estrada o avô desmontou para verter água. Verteu.

No intervalo Floripa virou a cara pro lado do Sítio. E parou.

Meu avô amontou de novo e apertou a marcha. Logo Floripa estacou em frente de nossa casa. Meu avô entrou e disse: Gostei de ver a Capital. Já tem até vaca na rua! É fruto de progresso. Floripa estava parece que rindo na porta.

(BARROS, 2007b, p.43)

O poema, composto por versos brancos e livres, típicos da literatura contemporânea, apresenta uma estrutura peculiar que permite traçar um paralelo entre ele e uma narrativa curta, mas não se confunde com esta, pois a disposição das frases, algumas vezes entrecortadas para a construção dos versos, assim como sua presença em um livro de poesias o caracterizam como um texto poético. Poesia que, saliente-se, é construida com elementos que, habitualmente, não pertencem ao universo da lírica como, por exemplo, "vadias" e "bandarra". Esses elementos são requisitados por Manoel de Barros como verdadeiros materiais poéticos e acabam por enriquecer sua escrita e formar imagens inusitadas que instigam e desafiam o leitor. Além disso, as palavras que compõem o texto são 
simples, mas marcam bem o tom do poema que, à primeira vista, parece ser puro divertimento, um mero provocador de risos.

Os fatos narrados possuem um ar de chiste, pois contam as trapalhadas de um avô que desejava passear na Capital, mas que, ao parar para fazer suas necessidades fisiológicas, "verter", é enganado por sua égua e acaba por retornar para casa antes de chegar ao seu objetivo. Esse senhor não percebe que não visitou a Capital e chega a fazer considerações sobre seu contentamento em perceber os avanços dela, que já possui vacas passando por suas ruas. O tom de piada, que permeia todo o poema, fica ainda mais caracterizado nesse momento em que o avô elogia o "progresso" da Capital, pois o que ele salienta como tal característica é, na verdade, um símbolo de atraso, de algo diretamente ligado ao ambiente campestre ou rural e que retrata bem o cotidiano das pequenas cidades interioranas.

A combinação de um poema que se apresenta como uma narrativa, a utilização de palavras corriqueiras e o tom de pilhéria, camuflam o teor social do texto. O deslocamento do avô de um Sítio para a Capital, já marca o grande abismo que existe entre esses dois espaços. O primeiro é imediatamente ligado, pelo leitor, a um lugar afastado, sem avanços tecnológicos, onde há animais soltos pelas ruas, como o próprio texto afirma que há, e onde se pode ter uma vida mais pacata e com maior contato com a natureza. Já a Capital, traz à mente aquela imagem da cidade grande, modernizada, em que há automóveis para todos os lados e edifícios rasgam os céus. O avô provavelmente nunca havia visitado a tal cidade, mas com certeza ouviu histórias sobre ela e como não chegou efetivamente ao seu destino, achou que a Capital havia progredido a tal ponto que já poderiam ser vistas vacas transitando pelas ruas. Ao estabelecer a presença de um animal como marca do progresso, Manoel de Barros ironiza o próprio conceito de desenvolvimento e deixa transparecer uma crítica implícita à sociedade, que está tão mecanizada e iludida com os avanços das tecnologias, que não consegue ter espaço para a natureza e para o próprio homem. O elogio do avô marca, na verdade, 
uma crítica à sociedade, que esqueceu suas origens e que não mais consegue observar a importância da natureza e de seus elementos.

Somente um texto produzido numa era tão mecanizada, em que os homens se afastam cada vez mais ao se trancafiarem em seus prédios e carros com vidros escurecidos, em que o comum, o trivial, perdeu o mérito, num mundo onde a máquina possui mais importância que um animal, que é, antes de tudo, um ser vivo, somente um homem inserido nesse contexto poderia exaltar um tal "progresso" que se caracteriza por uma vaca transeunte.

O outro texto escolhido para mostrar a presença do social na obra de Manoel Barros é o décimo poema que compõe a parte denominada "Desejar ser", presente no Livro sobre nada e que se reproduz abaixo:

Mosca dependurada na beira de um ralo -

Acho mais importante do que uma joia pendente.

Os pequenos invólucros para múmias de passarinhos que os antigo egipcios faziam

Acho mais importante do que o sarcófago de [Tutancâmon.

O homem que deixou a vida por se sentir um esgoto Acho mais importante do que uma Usina Nuclear.

Aliás, o cu de uma formiga é também muito mais importante do que uma Usina Nuclear.

As coisas que não têm dimensões são muito [importantes.

Assim, o pássaro tu-you-you é mais importante por seus pronomes do que por seu tamanho de crescer.

É no ínfimo que eu vejo a exuberância.

(BARROS, 2006, p.55) 
Nesse poema, o eu-poético apresenta ao leitor uma espécie de critério para apontar a importância que as coisas possuem. Sua lógica é invertida, pois é o ínfimo que passa a merecer destaque e acaba por ganhar status de coisa maior, enquanto aquilo que geralmente possui grande valor para a sociedade é considerado como algo de menor importância. Por esse motivo, destaca o mérito da mosca que está à beira de um ralo em demérito de uma joia e, até mesmo, consegue exaltar o ânus de uma formiga e um homem sofrido por se achar um nada, em detrimento de uma Usina Nuclear.

A explicação sobre a forma utilizada para medir a importância das coisas a sua volta é observada no verso "É no ínfimo que vejo a exuberância", ou seja, é no mais simples, mais inferior, no mínimo, que ele enxerga o belo, ele consegue perceber o que há de mais vigoroso naquilo que normalmente é rejeitado. É interessante notar que a importância do pássaro tuiuiú é medida pelos "pronomes" que apresenta, pois sonoramente o nome lembra os pronomes tu e you. A combinação tu, você e você intensifica a força dessa palavra, enfatizando-a, pois aponta três vezes para um mesmo "tu"; além disso, a sonoridade da prosopopeia torna o vocábulo ainda mais belo. Assim, a combinação de pronomes sugerida pela palavra estabelece sua importância, o tuiuiú se torna grande, independentemente do tamanho físico que venha a atingir, pelo campo de possibilidades poéticas que é aberto por seu nome.

Os confrontos estabelecidos no poema relacionam elementos tão distintos que o leitor quase não consegue perceber algum fio condutor que possa ligar tais elementos a ponto de opô-los de uma forma que se aproxima da antítese. Mas o propósito dessas colocações é exatamente causar um choque no leitor, colocá-lo em terreno arenoso, onde não se sinta familiarizado e tenha suas bases da lógica e da coerência estremecidas. Desse modo, o eu-poético consegue desfazer a ideia comum de importância, renegando aquilo que normalmente é visto como fonte de valor inestimável, através de 
um contraponto com elementos extremamente simplórios os quais elege como essenciais e exuberantes.

Outra questão evidenciada no texto é a da utilidade. Manoel de Barros, em suas obras, foge do conceito comum do que é útil e busca nas coisas mais infimas, corriqueiras, ou mesmo despreziveis, a utilidade que as pessoas ali não percebem ou não querem enxergar. Adorno (1998, p. 107) afirma que quando realmente existir uma ordem social que anule a irracionalidade arraigada na produção de mercadorias "a falta de utilidade não será mais uma vergonha. A adaptação perderá seu sentido. Somente então a produtividade agirá sobre a necessidade em um sentido autêntico, não desfigurado: não para saciar o insatisfeito com coisas inúteis, mas para possibilitar que a satisfação se relacione com o mundo sem ter de guiar-se pelo princípio da utilidade universal." E é isso que se percebe no universo poético de Barros: uma despreocupação como o "princípio da utilidade universal". Talvez isso ocorra exatamente por seu olhar estar voltado para as coisas mais simples ou ligadas a terra e à natureza e por sua rejeição ao que é industrializado ou possui mero valor mercadológico, como se pode observar nesse poema. O conceito de utilidade de Barros se afasta do olhar comum para associar-se a uma percepção interior, pessoal, e, por isso, impar. Assim, qualquer mosca, passarinho, homem que se sente como um esgoto, ou formiga, é útil para sua escrita, merece sua estima e passa a ser matéria de sua poesia.

Há outro ponto que merece ser destacado não apenas nos poemas que foram aqui utilizados como exemplos, mas em toda escrita de Manoel de Barros: a fragmentação do discurso. Sua linguagem é fragmentada de tal maneira que, algumas vezes, a informação parece estar entrecortada, incompleta ou mesmo sem sentido. Sobre esse assunto o próprio autor afirma que:

Cada vez mais. O próprio mundo está obrigando a gente a se fragmentar. É uma falta de unidade, o 
homem moderno não tem mais as grandes unidades, como Deus. A gente não tem crença em mais nada, aliás, toda a arte deste século é fragmentada, ninguém defende mais uma ideologia, hoje. O homem não acredita mais nem em ideologia, as religiões estão se fragmentando, o protestantismo está se dividindo, o cristianismo (BARROS, 2008).

Essa explicação de Barros mostra que sua arte é também reflexo de um mundo que está se fragmentando, e que o próprio processo da escrita não consegue se desvencilhar desse momento de múltiplas divisões que a sociedade contemporânea vivencia. Obra e sociedade estão ligadas por um fio quase que imperceptivel, mas que se revela nas entrelinhas.

E é dessa maneira que a lírica e a sociedade se relacionam nas obras de Manoel de Barros, não de maneira explícita ou forçada com o objetivo de impor uma visão ou simplesmente expor uma crítica ofensiva ao social, mas de forma interna à própria escrita, que acontece quase que involuntariamente e se apresenta no campo do subentendido. Há, então, na escrita de Barros uma consolidação da relação entre sujeito e sociedade e, como afirma Adorno (2003, p. 72): "Esse processo de sedimentação será tanto mais perfeito quanto menos a composição lírica tematizar a relação entre o eu e a sociedade, quanto mais involuntariamente essa relação for cristalizada, a partir de si mesma, no poema.”

Adorno (p. 67) nos mostra que a interpretação social da lírica não deve ter por objetivo a posição social da obra ou a inserção dos interesses dessa obra, ou mesmo do autor, na sociedade; antes, deve estabelecer de que maneira o todo da sociedade está presente no texto, apontando onde ele permanece submisso e onde supera a sociedade. E foi esse o objetivo do presente trabalho: mostrar em que ponto a escrita de Manoel de Barros ultrapassa as limitações impostas pelos valores difundidos na sociedade. Acredita-se que essa 
ultrapassagem ocorra inicialmente na linguagem, que se apresenta, quase sempre, de forma fragmentada, e se espalhe pela temática e pela inversão dos conceitos de utilidade, importância e conhecimento. Barros consegue, assim, através de uma subversão da lógica e da instauração de um mundo novo, trazer o social e o universal para sua escrita.

\section{Referências bibliográficas}

ADORNO, Theodor W. "Palestra sobre lírica e sociedade". In: Notas de Literatura I. Trad. Jorge Mattos Brito de Almeida. São Paulo: Duas Cidades / Editora 34, 2003.

. "Aldous Huxley e a utopia." In: Prismas - critica cultural e sociedade. Trad. Augustin Wernet e Jorge Mattos Brito de Almeida. São Paulo: Ática, 1998.

BARBOSA, Luiz Henrique. Palauras do chão: um olhar sobre a linguagem adâmica em Manoel de Barros. São Paulo: Annablume / Belo Horizonte: Fumec, 2003.

BARROS, Manoel de. Gramática expositiva do chão. 6. ed. Rio de Janeiro: Record, 2007(a).

. Livro sobre nada. 12. ed. Rio de Janeiro: Record, 2006.

. Matéria de poesia. 5. ed. Rio de Janeiro: Record, 2001.

. O guardador de águas. 2. ed. Rio de Janeiro: Record, 1998.

- O tema da minha poesia sou eu mesmo. Disponivel em: www.secrel.com.br/jpoesia/barros04.html. Acesso em: 05 dez. 2008. Entrevista concedida a André Luís Barros.

Poemas rupestres. 4. ed. Rio de Janeiro: Record, 2007(b). 